\title{
A new cryopathic syndrome
}

\author{
M CAUDRON, ${ }^{*} \dagger+$ C BIEVA, $\dagger$ E LAURENT, $\ddagger$ F DE MEUTER, $\|$ \\ WW FEREMANS, $\uparrow P$ LEBAS,** AND CL MALMENDIER $§$
}

From the Departments of ${ }^{*}$ Haematology, †Immunology, and $\ddagger$ Haematology, and $\S$ the Laboratory of Clinical Chemistry, St Pierre University Hospital, Brussels; ||Institut Pasteur du Brabant, Brussels; $\mid$ Laboratory of Pathology and Electron Microscopy, Free University of Brussels; **Institut Ophtalmologique, Mons; and ††MAB Laboratory, Mons, Belgium

SUMMARY One case of a syndrome simulating a systemic disease is reported. An HLA-B patient $_{\mathbf{8}}$ presented with apparent toxoplasmosis, retinal vein occlusion, autoantibodies against cephalin, contact factors and lipoproteins, immune complexes, rheumatoid factor, and cryoprecipitate. A representation of the immunological mechanisms involved is proposed.

A circulating anticoagulant has already been found in certain normal and pathological conditions: after childbirth, in apparently healthy elderly subjects, in women after parturition, after surgery, in infections, and in malignant and some other diseases such as haemophilia, systemic lupus erythematosus, rheumatoid arthritis, bullous dermatosis, regional enteritis, and hepatic disorders. ${ }^{1}$ The association of circulating anticoagulant with biological falsepositive reactions for syphilis was reported by Frick, in $1955,{ }^{2}$ in systemic collagen disease. This circulating anticoagulant is a protein found in the immunoglobulin fraction. Two years later, Laurell and Nilsson $^{3}$ reported two cases with circulating anticoagulant, false-positive syphilis reactions, and an associated hypergammaglobulinaemia. In 1969, Glueck et al. ${ }^{4}$ described hyperlipoproteinaemia, dysglobulinaemia, and a coagulation defect with systemic lupus erythematosus, and M'Seffar et al., in 1978,5 reported the association of cryoprotein, immune complexes, and rheumatoid factor in connective tissue diseases.

Toxoplasma infection may be associated with abnormal biological test results such as circulating anticoagulant, false-positive reactions for syphilis, hypergammaglobulinaemia with cryoprecipitate, hyperlipidaemia, immune complexes, and rheumatoid factor and then mimics a systemic disease. We report an HLA-B 8 patient with toxoplasmosis, autoimmune abnormalities, and retinal vein occlusion. The problem of this unusual association is reviewed in the light of recent knowledge of immunological mechanisms.

Received for publication 7 January 1980

\section{Material and methods}

\section{CASE REPORT}

A 50-year-old Caucasian woman was admitted to hospital in November 1977 because of rapidly failing vision. For one year she had had severe left occipital and frontal headaches. The fundus of the right eye was normal, but on the left side the veins were congested and a discrete papillar haemorrhage was visualised. For six months the erythrocyte sedimentation rate had been $34 \mathrm{~mm} / \mathrm{h}$. Two months before admission the patient experienced intermittent unilateral blurring of vision. There was a history of goitre but no other relevant history. The patient had not received oestrogen preparations and manifested no cold intolerance. There was a cat in the house but no culture of the pet's faeces had been made. Physical examination of this patient was normal except for a firm thyroid nodule. An electrocardiogram demonstrated a few premature auricular beats. Radiological screening, cerebral and thyroid scans, and bone marrow examination were all normal. Ocular examination showed an abnormal fundus of the left eye with retinal vein occulsion and a visual acuity of $4 / 200$ from $180 / 200$.

\section{Laboratory findings}

Urinary, haematological, and ionic values were normal. Total serum proteins were $7.3 \mathrm{~g} / \mathrm{dl}$ with $54.1 \%$ albumin, $2.7 \% \alpha 1,6.8 \% \alpha 2,9.5 \% \beta$, and $26.9 \% \gamma$ globulins. Quantitative determination of immunoglobulins gave $2.250 \mathrm{mg} / 100 \mathrm{ml}(22.5 \mathrm{~g} / \mathrm{l})$ IgG $(\mathrm{N}<17.2 \mathrm{~g} / \mathrm{l}), 1100 \mathrm{mg} / 100 \mathrm{ml}(11 \mathrm{~g} / \mathrm{l})$ IgM $(\mathrm{N}<2.8 \mathrm{~g} / \mathrm{l})$, and $145 \mathrm{mg} / 100 \mathrm{ml}(1.45 \mathrm{~g} / \mathrm{l}) \mathrm{IgA}$ $(\mathrm{N}<3.95 \mathrm{~g} / \mathrm{l})$. Serum immunoelectrophoresis 
Table 1 Ophthalmological and laboratory findings

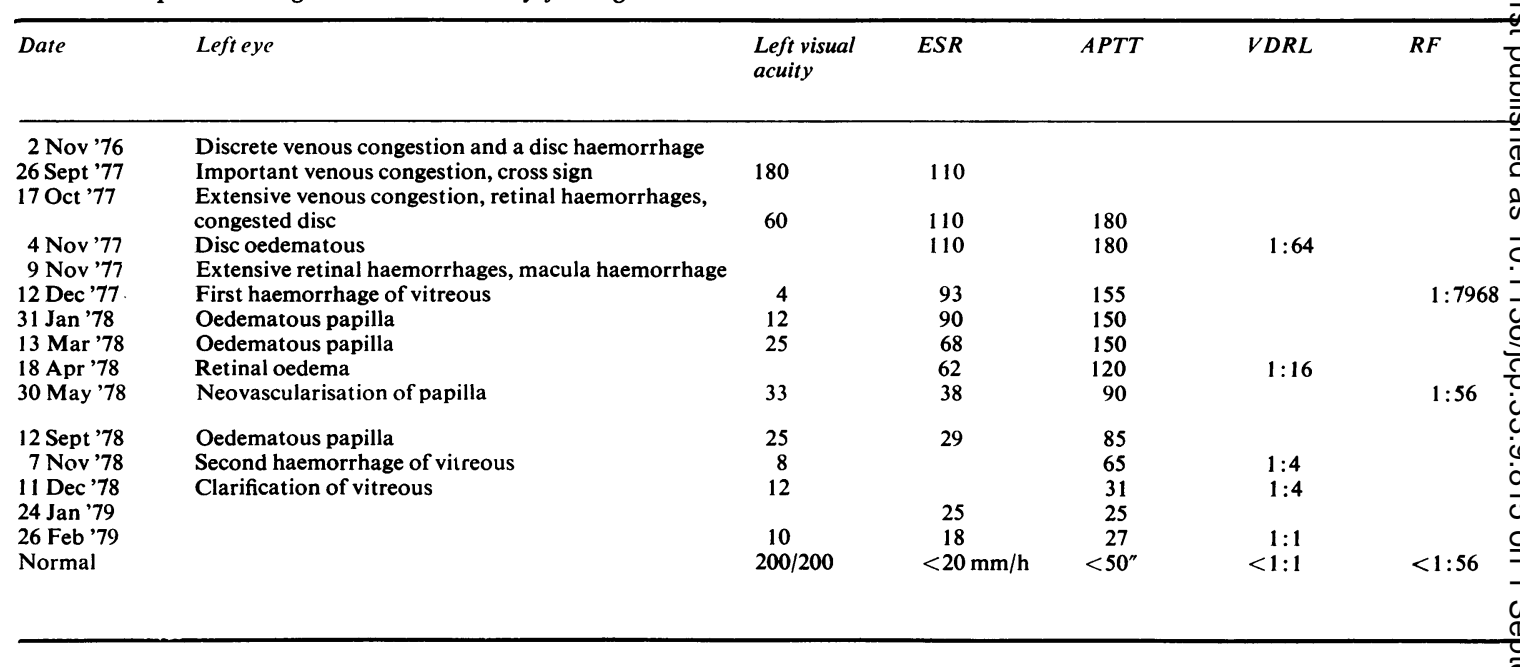

ESR $=$ erythrocyte sedimentation rate; APTT = activated partial thromboplastin time; VDRL =Venereal Disease Research Laboratory; RF = rheur factor.

showed polyclonal precipitin arcs with human antiIgG and anti-IgM antisera. SGOT was $12 \mathrm{IU} / \mathrm{l}$ $(\mathrm{N}<20)$, SGPT $50 \mathrm{IU} / \mathrm{l}(\mathrm{N}<17)$, and gammaglutamyl transferase $82 \mathrm{IU} / 1(\mathrm{~N}<25)$. Fluorescent treponema antibody was negative and treponema pallidum haemagglutination was non-specific. The other pathological results with the associated ophthalmological findings are detailed in Table 1.

\section{COAGULATION STUDIES}

The recalcification, prothrombin, thrombin and activated partial thromboplastin (APTT) clotting times, fibrinogen and fibrin degradation products measurements, and quantitative assays for factors II, V, VII, VIII, IX, X, XI, and XII were performed according to previously described methods. ${ }^{6}$ Factor VIII-RA was measured by rocket electrophoresis. ${ }^{7}$ A circulating anticoagulant against factors participating in the intrinsic clotting pathway was first detected by determination of APTT measured on a mixture of normal plasma $(0.9 \mathrm{ml})$ and various dilutions of the patient's plasma $(0 \cdot 1 \mathrm{ml})$. The dilutions prepared with barbital saline buffer $(\mathrm{pH}$ $7 \cdot 35$ ) varied from $1 / 2$ to $1 / 160$. These tests were performed after a 4-hour incubation at $37^{\circ} \mathrm{C}$. To demonstrate the specificity of the inhibitor, assays of factors V, VIII, IX, X, XI, and XII were performed on mixtures of normal plasma and dilutions of patient's plasma. Detection of an inhibitor of the contact phase of blood coagulation was according to Zucker et al. ${ }^{8}$ The inhibitory effect was quantified by comparing the clotting time of the patient's plasma with a dilution curve of contact factors. Neutralisa- tion of the circulating anticoagulant was performed using rabbit anti-human $\mu$ chain and $\gamma$ chain antisera (Dako, Copenhagen). ${ }^{9}$

\section{IMMUNOFLUORESCENCE STUDY}

In order to identify the patient's antibodies, these were coupled with fluorescein isothiocyanate, and a direct fluorescence test was performed on formol Toxoplasma.

\section{Electron microscopy}

The cryoprecipitate was treated as previously described. ${ }^{10}$

\section{Immunochemical analysis}

Blood was drawn with a warmed syringe and allowed to clot at $37^{\circ} \mathrm{C}$. The serum was stored at $4{ }^{\circ} \mathrm{C}$ for 24 hours. The cryoprecipitate was isolated by centrifugation $(2000 \mathrm{rpm})$ for 30 minutes at $4^{\circ} \mathrm{C}$, washed twice with saline, lyophilised, and stored at $-20^{\circ} \mathrm{C}$. Electrophoresis, immunoelectrophoresis, and immunofixation were performed according to the usual methods.

\section{Immunology}

Patient's plasma was submitted to ultracentrifugation to detect the antilipoprotein activity of immunoglobulins. The antibody activity of the immunoglobulin fraction (density (d) $<1.021$ ) was tested by double-immunodiffusion (Ouchterlony) in $1 \%$ agar gel plates against the lipoprotein fraction $(\mathrm{d}<1.019$, $1.019<\mathrm{d}<1.063$, and $1.063<\mathrm{d}<1.21$ ). 


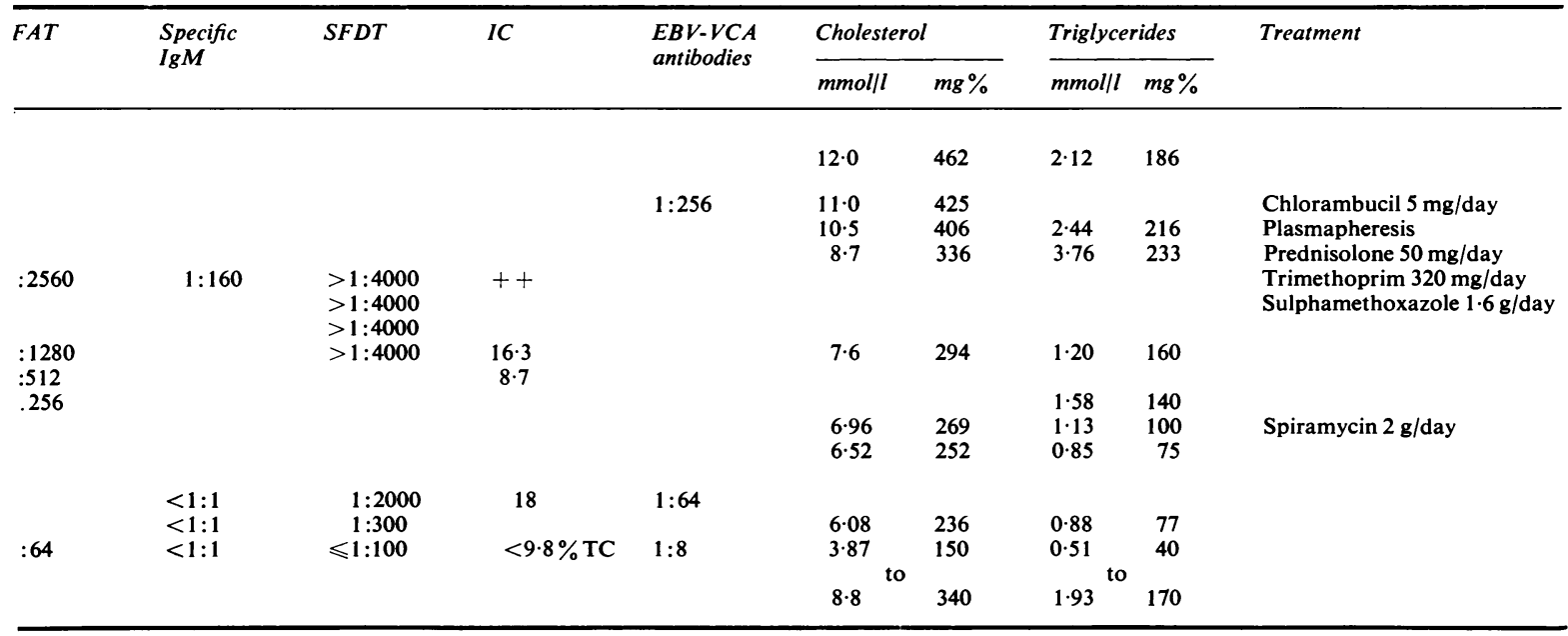

FAT $=$ indirect fluorescent antibody test SFDT $=$ Sabin Feldman dye test $;$ IC $=$ immune complexes $;$ TC $=$ total count EBV-VCA $=$ Epstein Barr virus capsid antigens.

Lipid analysis

Lipid extraction of the cryoprecipitate was performed with chloroform-methanol $(2: 1)$ and then thin-layer chromatography (TLC) of the neutral lipids in ether-hexane-acetic acid $(20: 80: 1)$ and of phospholipids in chloroform-methanol-water $(65: 25: 4)$. Spots corresponding to cholesterol esters, triglycerides, free fatty acids, free cholesterol, lecithin, sphingomyelin, and lysolecithin were revealed by iodine vapour.

\section{Results}

COAGULATION

The first haemostatic profile revealed an extension of the APTT and a nearly normal prothrombin time (Table 2). Two plasmaphereses carried out within a four-day interval yielded a slight but transient improvement of the coagulation tests. Prolonged clotting times returned rapidly, and corticosteroid therapy was tried for one week without success. Intravascular coagulation disease was ruled out by the low level of fibrin degradation products $(<10$ $\mathrm{mg} / \mathrm{l})$.

Tests were performed to detect a circulating anticoagulant inhibitory effect against several clotting factors. Mixtures of dilutions of the patient's plasma and of control plasma yielded a prolonged clotting time in APTT, thrombin time, and V, VIII, IX, X, and $\mathrm{XI}$ factor assays. Clotting times were markedly pro-

Table 2 Coagulation tests

\begin{tabular}{|c|c|c|c|c|c|c|c|c|c|c|}
\hline & \multicolumn{4}{|c|}{ Plasmapheresis } & \multirow{2}{*}{\multicolumn{2}{|c|}{$\frac{\text { Methylprednisolone }}{30 \text { Nov'77 } 7 \text { Dec '77 }}$}} & \multicolumn{3}{|c|}{ Sulphamethoxazole trimethoprim } & \multirow{3}{*}{$\begin{array}{l}\text { Normal } \\
\text { range }\end{array}$} \\
\hline & \multicolumn{2}{|c|}{4 Nov'77 } & \multicolumn{2}{|c|}{8 Nov'77 } & & & \multirow{2}{*}{\multicolumn{2}{|c|}{$14 \mathrm{Dec}$ '77 $19 \mathrm{Apr}$ '78 }} & \multirow[t]{2}{*}{$4 \mathrm{Oct}{ }^{\prime} 78$} & \\
\hline & Before & After & Before & After & Before & After & & & & \\
\hline Platelet count $\left(10^{\circ} / 1\right)$ & 324 & 190 & 225 & 219 & & & & & & $150-350$ \\
\hline \multicolumn{11}{|l|}{ Activated partial } \\
\hline thromboplastin time (s) & 180 & 97 & 106 & 75 & 158 & $>240$ & 100 & 80 & 50 & $25-55$ \\
\hline Prothrombin time (s) & 13 & $14 \cdot 8$ & $16 \cdot 7$ & $16 \cdot 5$ & $>38$ & $>38$ & $14 \cdot 2$ & $14 \cdot 8$ & $13 \cdot 4$ & $11 \cdot 4$ \\
\hline Thrombin time (s) & 23 & 22 & $22 \cdot 4$ & 24 & $>120$ & $>120$ & $19 \cdot 8$ & $19 \cdot 8$ & $20 \cdot 8$ & $18-22$ \\
\hline Fibrinogen $(g / l)$ & & $1 \cdot 6$ & $2 \cdot 3$ & $1 \cdot 7$ & $1 \cdot 8$ & 1.9 & $2 \cdot 6$ & $3 \cdot 1$ & $2 \cdot 7$ & $2 \cdot 0-4 \cdot 0$ \\
\hline FDP (mg/l) & & & & & & $<10$ & & & & 20 \\
\hline \multicolumn{11}{|l|}{ Factor levels (\%) } \\
\hline II & & 65 & 70 & 65 & 35 & 45 & 95 & 97 & 95 & $60-130$ \\
\hline V & & 50 & 40 & 30 & 10 & 25 & 25 & 35 & 100 & \\
\hline $\mathbf{V I I}+\mathbf{X}$ & & 85 & 90 & 85 & 25 & 30 & 85 & $>100$ & 100 & \\
\hline $\mathrm{X}$ & & 55 & & 35 & 40 & $<10$ & 45 & 35 & 45 & $70-130$ \\
\hline VIII & & & & & & 0 & & 24 & 65 & $50-150$ \\
\hline IX & & & & & & 0 & & 87 & 95 & $60-160$ \\
\hline XI & & & & & & 0 & & 50 & 70 & 63-136 \\
\hline XII & & & & & & 0 & & 54 & 80 & $22-253$ \\
\hline VIII-related antigen & & & & 125 & & & & & 130 & $70-130$ \\
\hline
\end{tabular}


longed when tests were performed with low dilutions of the patient's plasma and they returned to normal with high dilutions (Table 3). Incubation of the patient's plasma for 4 hours at $37^{\circ} \mathrm{C}$ did not alter the results. Prolongation of the clotting times was more obvious when tests were performed after storage of the patient's plasma for 24 hours at $-20^{\circ} \mathrm{C}$. The patient's plasma inhibited $98 \%$ of the contact products. This inhibitory activity was present immediately and also after 15-minutes' incubation. It was already detected by using contact products at a dilution of $1 / 2$ (Table 4 ).

The anticoagulant effect disappeared completely after neutralisation with anti-IgM serum and partially after anti-IgG serum. The long APTT obtained with the patient's plasma (108 seconds $2 / 10$ ) returned to a normal value (56 seconds 4/10) after neutralisation of the plasma with antiIgM serum and to a better one ( 75 seconds 4/10) after neutralisation with anti-IgG serum. The neutralisation of the anticoagulant by anti-IgM serum resulted in normal factors VIII, IX, XI, and XII assays.

During the subsequent six months, the potency of this inhibitor decreased during sulphamethoxazoletrimethroprim treatment, and the anticoagulant was no longer detectable 11 months after the beginning of treatment.
IMMUNOFLUORESCENCE

The direct fluorescent-antibody test for $T$. gondii was positive at a $1 / 2$ dilution of the patient's immunoglobulins.

\section{ELECTRON MICROSCOPY}

The cryoprecipitate presented a fibrillar ultrastructure and a proteinaceous appearance (Fig. 1).

\section{CHEMISTRY AND IMMUNOCHEMISTRY}

The serum was viscous and formed large gel-like lumps at room temperature. The cryoprecipitate was $690 \mathrm{mg} / 100 \mathrm{ml}$. Cryoprecipitate treated with alkylating or reduction agents did not react when tested against various antisera. On agar gel electrophoresis the solubilised cryoprecipitate showed one band of $\gamma$-mobility (stained with Coomassie Brilliant Blue FF) and another of $\beta$-mobility (stained with Fad Red B). Chloroform-methanol extracts of the cryoprecipitate showed the presence of $5 \%$ of lipids. Thin-layer chromatography of neutral lipids and phospholipids showed patterns similar to those of a normal plasma but the number of washings excluded the possibility of contamination by plasma. On double-diffusion plates (Fig. 2), patient's plasma immunoglobulins prepared by ultracentrifugation $(\mathrm{d}<1.021)$ reacted with patient's plasma VLDL +

Table 3 Inhibitory activity against coagulation factors

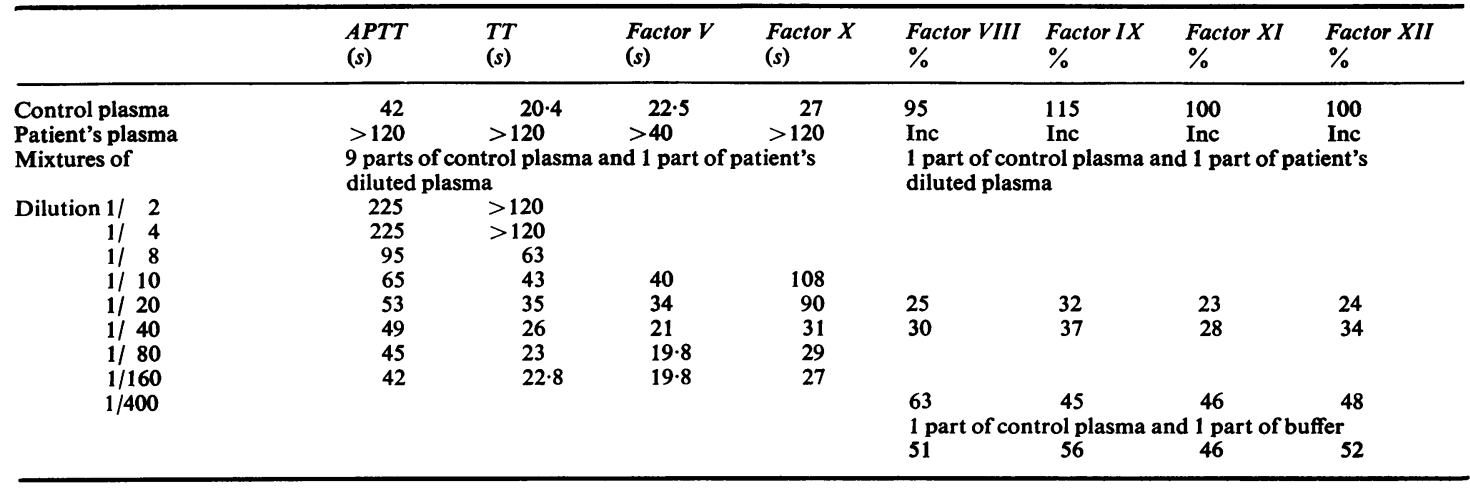

Inc $=$ incoagulable.

Table 4 Inhibition of contact products by the patient's serum

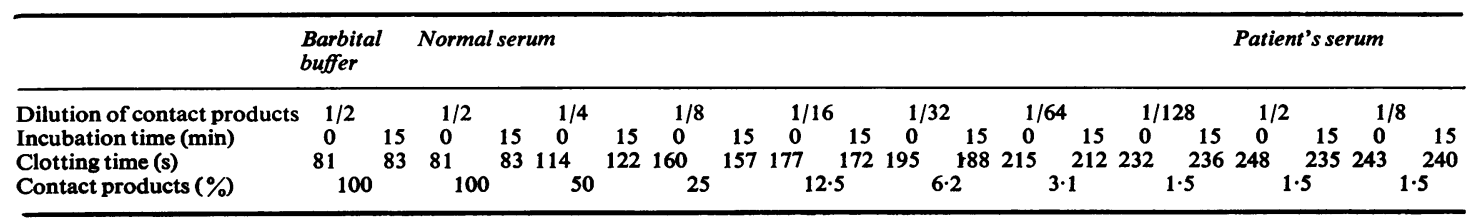




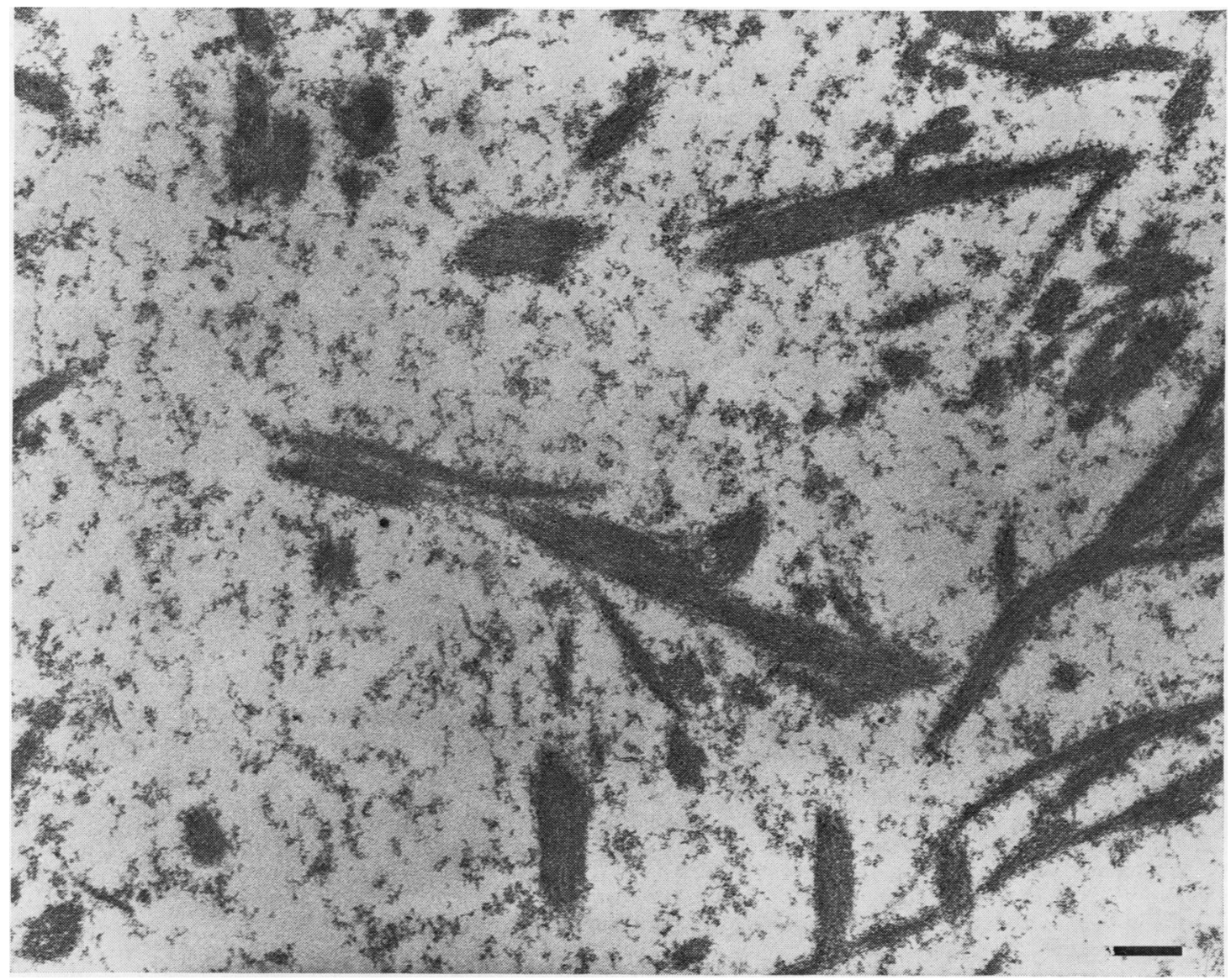

Fig. 1 Electron micrograph of cryoprecipitate. Original magnification $\times 50000$. Calibration bar $0.2 \mu \mathrm{m}$.

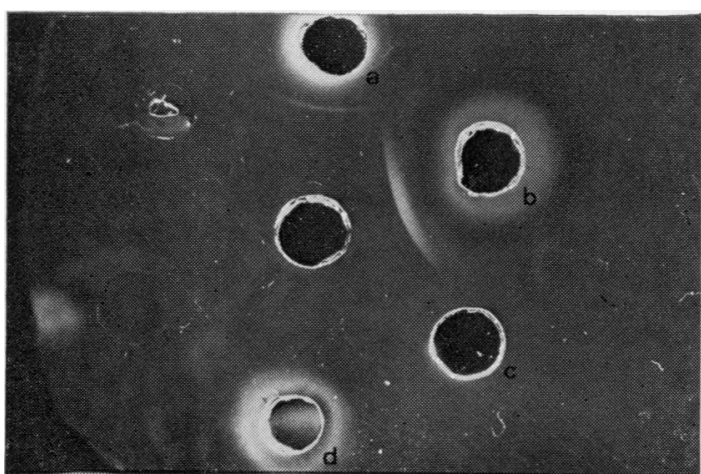

Fig. 2 Double-diffusion in agar of concentrated plasma IgM in centre well and plasma lipoprotein fractions in exterior wells: (a) $V L D L+I D L$; (b) $L D L$; (c) $H D L$; (d) normal serum.
IDL $(\mathrm{d}<1.019)$ and LDL $(1.019<\mathrm{d}<1.063)$. No reaction was visualised with $\mathrm{HDL}$.

\section{Discussion}

Three groups of aetiological factors, abnormal blood flow patterns, vessel wall, and blood constituents (Virchow triad), are commonly considered in retinal vein occlusion. ${ }^{11}$ In the present case, hypergammaglobulinaemia with cryoprecipitate, hyperlipidaemia, and activation of the extrinsic pathway of blood coagulation acted to cause a stagnation thrombosis (Fig. 3B). Since 1961, cryopathies have usually been referred to according to Ritzmann's classification. ${ }^{12}$ In our patient, classical criteria for cryofibrinogenaemia (elevated levels of $a_{1}$-antitrypsin and hyperfibrinogenaemia) and cryoglobulin 


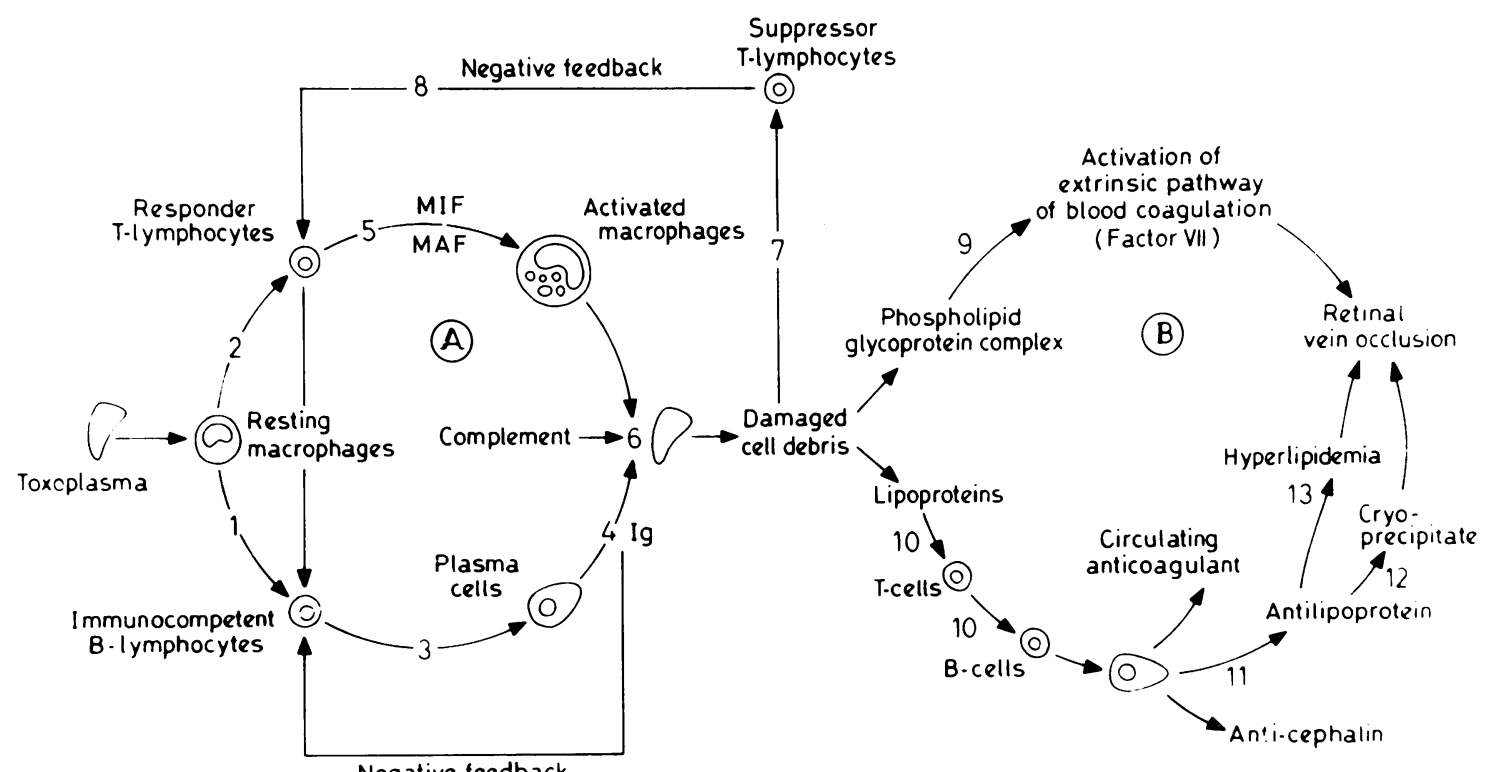

Fig. 3 Schematic representation of possible immunological mechanisms leading to retinal vein occlusion.

(A) Toxoplasma gondii is digested by resting macrophages which produce antigens activating B-lymphocytes $(I)$ and responder T-lymphocytes (2). Activated immunocompetent B-lymphocytes mature to plasma cells (3), which produce immunoglobulins inducing negative feedback on immunocompetent B-lymphocytes. Responder T-lymphocytes secrete lymphokinins, transforming resting macrophages into activated macrophages (5). Interaction of activated macrophages, complement, and immunoglobulins leads to destruction of $\mathrm{T}$. gondii with release of Toxoplasma and cellular debris (6). This damaged cell debris may act as immunosuppressive products and stimulate suppressor T-lymphocytes (7), which block the reaction of responder T-lymphocytes (8).

(B) Phospholipid glycoprotein complex from damaged cells activates factor VII and thus the extrinsic pathway of blood coagulation (9). Lipoproteins as new antigenic determinants generate responder T-lymphocytes, leading to $T$ and $B$ cell cooperation (10) with production of different autoantibodies (11), one against cephalin (positive VDRL), one against contact products (circulating anticoagulant), and one against lipoprotein constituting lipoprotein autoantibody immune complex with cryoprecipitation (12), lipoprotein lipase inhibition, and hyperlipidaemia (13). Activated coagulation, hyperlipidaemia, and cryoprecipitate cause retinal vein occlusion.

(thermal reversibility) were absent. Two families of serum IgM were considered, one with IgM antibodies directed against Toxoplasma gondii (Fig. 3A) and the other with IgM autoantibodies (Fig. 3B) against cephalin, contact factors, lipoproteins, and/or membranes. IgM autoantibodies against cephalin (positive VDRL) involved phospholipid antigens. ${ }^{13}$ Circulating anticoagulants can be regarded as a real autoantibody ${ }^{14}$ and are thought to be anti-thromboplastin. ${ }^{2}$ In the case of Laurell and Nilsson ${ }^{3}$, both serum antithromboplastin activity and non-specific Wassermann reactions were directed against lipids: thromboplastin and cardiolipin. The attack of thrombosis without bleeding and the nature of the coagulation's inhibitor (IgM) are characteristic of an interfering inhibitor similar to those in autoimmune disease $^{1}$ and in chlorpromazine-treated patients with inhibition of the contact activation phase. ${ }^{8}$ Autoantibodies against lipoproteins may be important in the pathology of dyslipidaemias, malignancies (Table 5), and hepatitis. ${ }^{15}$ In Table 5, the patient's autoantibody against lipoprotein is compared to that in other reported cases. According to Kodama, ${ }^{16}$ activity of such autoantibodies is directed against the lipid haptens (phospholipid groups) and not against the protein moiety of lipoprotein groups. ${ }^{16}$ Autoantibody against lipoprotein shares two characteristics reported in the literature: cryoprecipitation as lipoprotein-autoantibody immune complexes ${ }^{16}$ and inhibition of lipoprotein lipase activity with production of hyperlipidaemia. ${ }^{17}$ It seems possible that, in our patient, all three IgM autoantibodies (anti-cephalin, anti-contact products, and antilipoprotein) were similar or even identical. Another interesting problem is the role of circulating complexes 'which not always were the pathogenic cause of disease'. ${ }^{18}$ In a few cases, specific protozoa have been identified in human diseases with immune 
Table 5 Laboratory findings of autoantibodies against lipoproteins (survey of the literature)

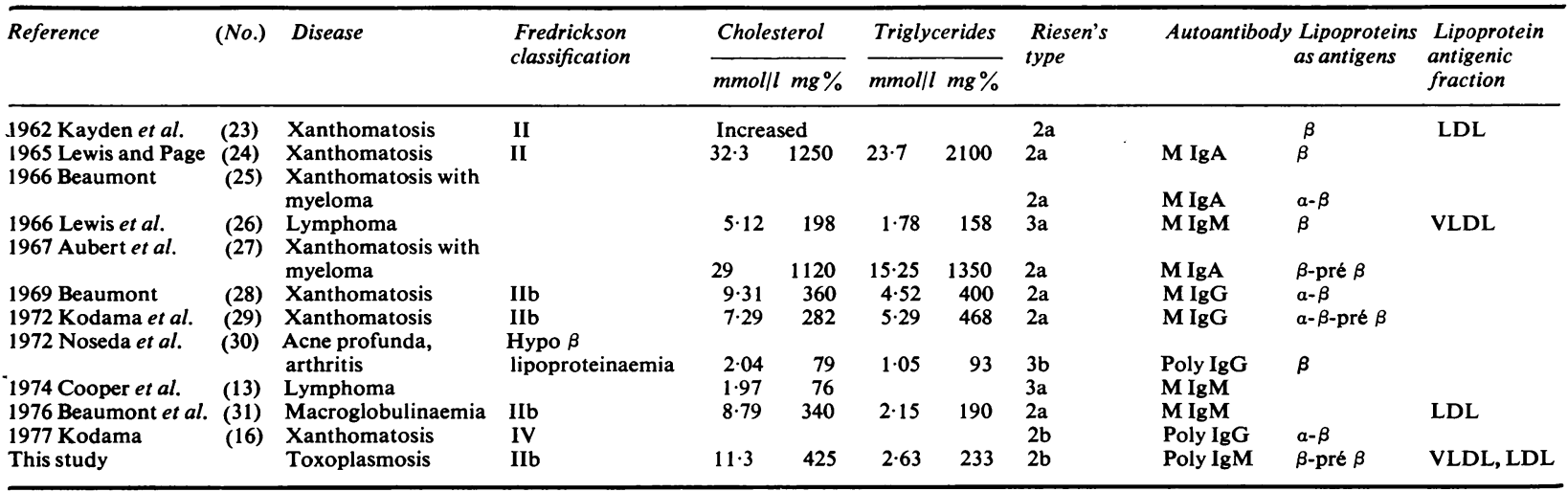

$\mathbf{M}=$ monoclonal; Poly $=$ polyclonal $; \mathrm{VLDL}=$ very low density lipoproteins; $\mathrm{LDL}=$ low density lipoproteins; $\mathrm{HDL}=\mathrm{high}$ density lipoproteins

complexes. ${ }^{19}$ According to the criteria of de Meuter et al., ${ }^{20}$ our patient was infected with $T$. gondii, but no Toxoplasma antigen was found in the cryoprecipitate. Lipoprotein antigens may be non-specific as damaged cell debris or serum lipoproteins. $T$. gondii is a parasite which eludes the immune response by adaptation to macrophages, may be found in haematological diseases and immunodepressed patients, and frequently causes retinochoroiditis but seldom other ocular lesions. ${ }^{21}$ These genetic (HLA-B 8 ), biological (autoantibodies), and clinical (retinal vein thrombosis) patterns are commonly associated with autoimmune disease. According to Eddleston, ${ }^{22}$ HLA-B ${ }_{8}$ was implicated in a defect of 'suppressor'-cell activity which would usually switch off autoantibody production in autoimmune diseases. ${ }^{22}$ In conclusion, the association of toxoplasmosis with retinal vein occlusion found in our HLA-B 8 patient has not been reported previously. Chemotherapy resulted in correction of the coagulation disorders, restitution of partial visual acuity, and a return to normal of the hyperlipidaemia and other biological parameters. However, the 18-month follow-up period is not yet sufficient to exclude an associated malignancy.

We are grateful to Professor A Govaerts, Dr R Denolin-Reubens, Dr C Robyn, and Dr PF Richard for a critical reading of the manuscript and to Dr A van Aerdt, Institut de Recherches Vétérinaires, Uccle, who has prepared immunosera for fluorescence studies. We thank Mrs J Gerard, C MullerHariga, CJ Finne, Th Lafontaine, and $\mathrm{Mr} \mathrm{JM}$ Famelart for technical assistance, Mr R Fauconier for the drawings, and Mrs L Lesne for typing the manuscript.

\section{References}

${ }^{1}$ Deutsch E. Acquired inhibitors in coagulation. In: Schmer G, Strandjord PE, eds. Coagulation: Current Research and Clinical Applications. New-York and London: Academic Press, 1973;135-48.

${ }^{2}$ Frick PG. Acquired circulating anticoagulants in systemic "collagen disease". Blood 1955;10:691-706.

${ }^{3}$ Laurell AB, Nilsson IM. Hypergammaglobulinemia, circulating anticoagulant, and biologic false positive Wasserman reaction. J Lab Clin Med 1957;49:694-707.

${ }^{4}$ Glueck CJ, Levy RI, Glueck HI, Gralnick HR, Greten H, Fredrickson DS. Acquired type I hyperlipoproteinemia with systemic lupus erythematosus, dysglobulinemia and heparin resistance. Am J Med 1969;47:318-24.

${ }^{5}$ M'Seffar A, Reynolds WJ, Weinstein A, Yue R, Broder I, Deck JHN. Connective tissue disease and hyper viscosity syndrome with cryoprotein and immune complexes. $J$ Rheumatol 1978;5:412-22.

- Austen DEG, Rhymes IL. A Laboratory Manual of Blood Coagulation. Oxford: Blackwell Scientific Publications, 1975.

${ }^{7}$ Zimmerman TS, Hoyer LW, Dickson L, Edgington TS. Determination of the Von Willebrand's disease antigen (factor VIII-related antigen) in plasma by quantitative immunoelectrophoresis. J Lab Clin Med 1975;86:1529.

${ }^{8}$ Zucker S, Zarrabi MH, Romano GS, Miller F. IgM inhibitors of the contact activation phase of coagulation in chlorpromazine-treated patients. Br J Haematol 1978; 40:447-57.

9 Feinstein DI, Rapaport SI, Chong MNY. Immunologic characterization of 12 factor VIII inhibitors. Blood $1969 ; 34: 85-90$.

10 Millonig G. Further observations on a phosphate buffer for osmium solutions. In: Breese SS, Jr. ed. Electron Microscopy: Proceedings of the Vth International Congress for Electron Microscopy. New York: Academic Press, 1962;8.

${ }_{11}$ McGrath MA, Wechsler F, Hunyor ABL, Penny $R$. Systemic factors contributory to retinal vein occlusion. Arch Intern Med 1978;138:216-20.

12 Ritzmann SE, Levin WC. Cryopathies: a review. Arch Intern Med $1961 ; 107: 754-72$.

${ }^{13}$ Cooper MR, Cohen HJ, Huntley CC, Waite BM, Spees L, 
Spurr CL. A monoclonal IgM with antibody-like specificity for phospholipids in a patient with lymphoma. Blood 1974;43:493-504.

14 Waldenström J. Circulating anticoagulants and disturbance of gammaglobulin formation. In: Monoclonal and Polyclonal Hypergammaglobulinemia: Clinical and Biological Significance. Cambridge: University Press, 1968; 141-8.

15 Jensen DM, McFarlane IG, Portmann BS, Eddleston ALWF, Williams R. Detection of antibodies directed against a liver-specific membrane lipoprotein in patients with acute and chronic active hepatitis. $N$ Engl $J$ Med 1978;299:1-7.

${ }^{16}$ Kodama H. Determination of cryoglobulins as lipoproteinautoantibody immune complexes and antigenic determinants against antilipoprotein autoantibody. Clin Exp Immunol 1977;28:437-44.

17 Beaumont JL. Auto-immune hyperlipidemia: an atherogenic metabolic disease of immune origin. Rev Eur Etud Clin Biol 1970;15:1037-41.

${ }^{18}$ Levinsky RJ. Role of circulating soluble immune complexes in disease. Arch Dis Child 1978;53:96-9.

19 Lambert PH, Houba V. Immune complexes in parasitic diseases. In: Brent L, Holborow J, eds. Progress in Immunology, II, vol 5. Amsterdam: North Holland Publishing Company 1974;57-67.

20 De Meuter F, De Decker $H$. La réaction d'immunofluorescence indirecte dans la toxoplasmose. L'avantage de l'emploi du conjugue fluorescent anti-IgG. Zentralbl Bakteriol [Orig A] 1975;233:421-30.

21 Willerson D Jr., Aaberg TM, Reeser F, Meredith TA. Unusual ocular presentation of acute toxoplasmosis. $\mathrm{Br} J$ Ophthalmol 1977;61:693-8.

22 Eddleston ALWF. Genetically determined immune hyperreactivity in human liver disease. Proc $R$ Soc Med 1977; 70:525-9.

${ }^{23}$ Kayden HJ, Franklin EC, Rosenberg B. Interaction of myeloma gamma globulin with human beta-lipoprotein. Circulation 1962;26:659-62.

24 Lewis LA, Page IH. An unusual serum lipoproteinglobulin complex in a patient with hyperlipemia. Am J Med 1965;38:286-97.

25 Beaumont JL. Une gamma-globuline de myélome douée d'une activité spécifique anti-lipoprotéine. L'autoanticorps anti-Pg. CR Acad Sci [D] (Paris) 1966;263: 2046-8.

${ }^{26}$ Lewis LA, Van Ommen RA, Page IH. Association of cold-precipitability with beta-lipoprotein and cryoglobulin. Am J Med 1966;40:785-93.

27 Aubert L, Arroyo H, Detolle P, Picard D, Cotte G. Etude clinique et cytologique d'un deuxième cas d'IgAmyélome xanthomateux avec auto-anticorps circulant anti-lipoprotéine. Sem Hóp Paris 1967;48:3014-21.

28 Beaumont JL. Un deuxième type d'auto-anticorps antilipoprotéine de myélome: l'IgG anti-Lp Al. CR Acad Sci Paris 1969;269:107-10.

${ }^{29}$ Kodama H, Nakagawa S, Tanioku K. Plane xanthomatosis with anti-lipoprotein autoantibody. Arch Dermatol 1972;105:722-7.

${ }^{30}$ Noseda G, Riesen W, Schlumpf E, Morell A. Autoantikörper gegen Lipoproteine und Hypolipidämie bei seronegativer primär-chronischer Polyarthritis. Schweiz Med Wschr 1972;102:969-81.

${ }^{31}$ Beaumont JL, Lorenzelli L, Delplanche B, Zittoun R, Homberg JC. A new serum lipoprotein associated erythrocyte antigen which reacts with a monoclonal IgM. Vox Sang 1976;30:36-49.

Requests for reprints to: Dr M Caudron, Department of Haematology, St Pierre University Hospital, Brussels, Belgium. 